\title{
Experimental Study on Blended Coal Combustion of 350MW Supercritical Boiler
}

\author{
Yingai Jin ${ }^{1,2}$, Kaijie Liang,a and Lu Jiao ${ }^{2}$ \\ ${ }^{1}$ State Key Laboratory of Automotive Simulation and Control, Jilin University, Changchun 130022 , \\ China \\ ${ }^{2}$ College of Automotive Engineering, Jilin University, Changchun, Jilin, 130022, China \\ aCorresponding author: 351409317@qq.com
}

Keywords: Blending coal, Thermogravimetric Analysis, Best mix ratio, Blending.

\begin{abstract}
In this paper, Hesi Wulai lignite, Shaltala lignite and Shanxi Gepu bituminous coal were selected to participate in experimental study in a 350MW supercritical boiler, the design coal of which is lignite. This study investigates the pyrolysis behavior of ten kinds of blended coal using thermogravimetric analysis at a heating rate of $20^{\circ} \mathrm{C} / \mathrm{min}$ to determine mass loss rates and firing temperature as a function of blend composition. This study also investigates the optimal blending ratio using the multi-objective fuzzy decision-making model with the coal price and sulfur content of blended coal being taken as objective functions. It was proposed that the optimal blending ratio of the Hesheger Ula lignite, Salta pull lignite and Shanxi Gepu bituminous coal was (4: 4: 3).
\end{abstract}

\section{Introduction}

In many countries, the issue of blended coal burning in power plants has been studied in detail according to its specific national conditions. In 1980s, a power plant coal blending system COMOSTM was successfully developed by the United States ${ }^{[1-2]}$. The research of blended coal combustion in Germany is mainly aimed at the combustion characteristics of blended coal and combustion equipment of blended coal. Japan's coal resources are relatively scarce. Therefore, blending anthracite coal with a certain proportion of other coal types to make combustion more stable has been the main direction of blended coal research in Japan ${ }^{[3]}$. Domestic scholars have also researched the law of mixed coal burning characteristics $^{[4-7]}$.

Several kinds of single coal Hesi Wula lignite, Shaltala lignite and Shanxi Ge Pu bituminous coal are blended in different proportions, and the safety, stability and boiler economy of the unit are tested under different operating parameters. However, there are few cases of blending lignite with bituminous coal in China, so it is necessary to do preparatory work in the early stage and fully analyze the combustion characteristics of coal, especially to make full use of the characteristics of bituminous coal.

\section{Experimental Study On Hot Weight Of Blended Coal}

Thermogravimetric analyzer has been taken using a HS-TGA-101. The main working principle of the instrument is by heating the crucible sample, so that its quality changes with the temperature changes, and then passed through the force sensor into the photoelectric sensor, and finally to attract the current in the coil changes, that is, the initial quality change Turned into a change in current, and both are proportional. And this process will automatically collect the data through the computer to draw TG-DSC curve, and finally the data output, TG-DTG with temperature changes in the curve, through the origin software for data processing and analysis of the sample ignition temperature.HS-TGA-101 thermogravimetric analyzer technical indicators as shown in Table 1. The test conditions are shown in Table 1. 
Table 1 HS-TGA-101 Thermogravimetric analyzer technical indicators

\begin{tabular}{|c|c|c|c|}
\hline Technical indicators & Instrument requirements & $\begin{array}{c}\text { Technical } \\
\text { indicators }\end{array}$ & Instrument requirements \\
\hline temperature range & $\begin{array}{c}\text { Room temperature } \\
\sim 1150^{\circ} \mathrm{C}\end{array}$ & $\begin{array}{c}\text { Temperature } \\
\text { control mode }\end{array}$ & $\begin{array}{c}\text { Heating up, constant } \\
\text { temperature, cooling }\end{array}$ \\
\hline $\begin{array}{c}\text { temperature } \\
\text { fluctuation }\end{array}$ & $\pm 0.1^{\circ} \mathrm{C}$ & Cooling time & $15 \min \left(1000^{\circ} \mathrm{C} \sim 100^{\circ} \mathrm{C}\right)$ \\
\hline $\begin{array}{c}\text { temperature } \\
\text { resolution }\end{array}$ & $0.1^{\circ} \mathrm{C}$ & $\begin{array}{c}\text { Balance test } \\
\text { range }\end{array}$ & $1 \mathrm{mg} \sim \mathrm{g}$ \\
\hline heating rate & $1 \sim 80^{\circ} \mathrm{C} / \mathrm{min}$ & Resolution & $0.1^{\mu g}$ \\
\hline $\begin{array}{c}\text { Constant temperature } \\
\text { time }\end{array}$ & $0 \sim 300 \mathrm{~min}$ & & \\
\hline
\end{tabular}

After the thermogravimetric test, the curve shown in Figure 1 is obtained. The corresponding point of the ignition temperature is $t$, that is, the temperature corresponding to the start of combustion of pulverized coal. When this is exceeded, the rate of weight loss of coal will increase rapidly. It is an important indicator of the degree of fire safety, the lower the ignition temperature, the corresponding coal is more likely to fire, usually using the thermal balance combustion curve determination, analysis different coal ignition temperature, therefore, the ignition temperature is an important measure of the degree of difficulty of coal ignition, and the lower the ignition temperature, the coal more likely to be fired.

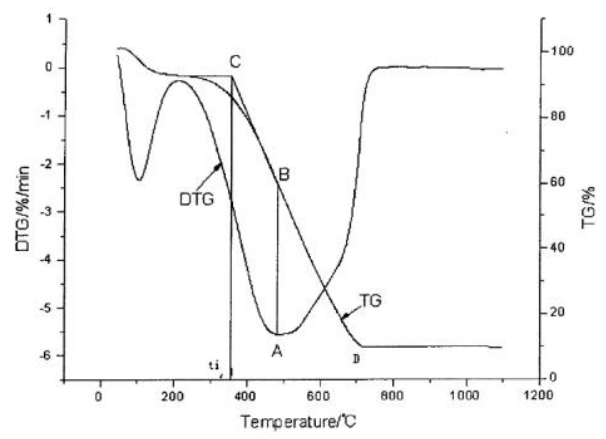

Figure 1 Fire temperature definition diagram

In addition, we can get the other two points through the above points: The maximum weight loss rate and its corresponding temperature, that is, the temperature $t_{f}$ corresponding to the point $A$ in the figure, when the TG curve is no longer significantly flattened, the D-point temperature is defined as the weight loss end temperature $T_{h}$. Maximum weight loss rate $(d W / d t)_{\max }$. The following is the TG-DSC curve and its analysis under different experimental conditions.

\subsection{Single Burning Coal Ignition Temperature}

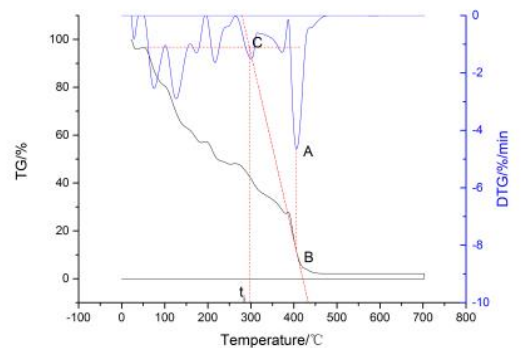

Figure2 Condition

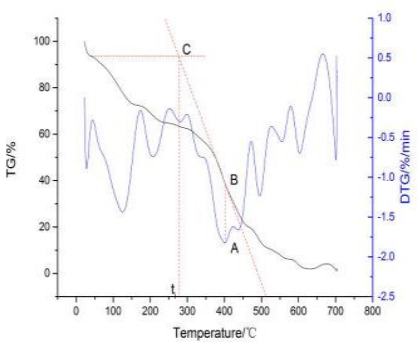

Figure3 Condition

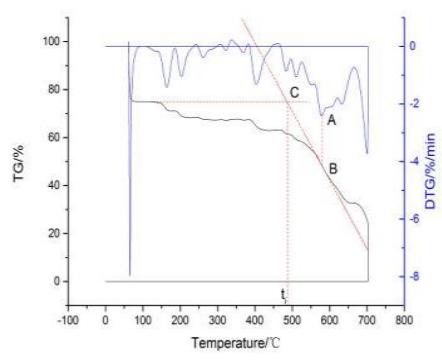

Figure 4 Condition

The firing temperatures of the Hezig Ura coal, the Shaltara coal and the Shanxi Gepu coal were $300{ }^{\circ} \mathrm{C}, 280{ }^{\circ} \mathrm{C}, 490{ }^{\circ} \mathrm{C}$ 


\subsection{Two Kinds of Coal Mixed Fire Temperature}

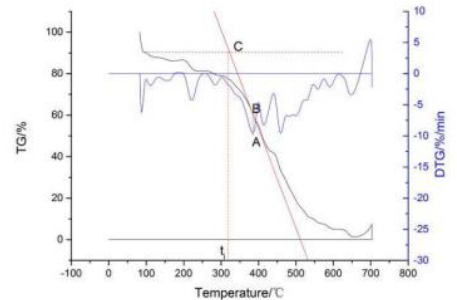

Figure5 Condition

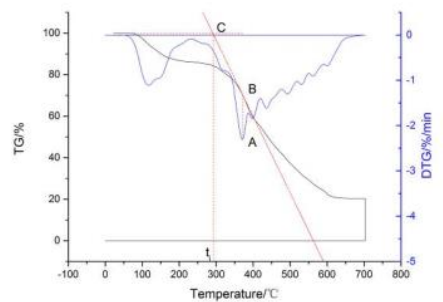

Figure6 Condition

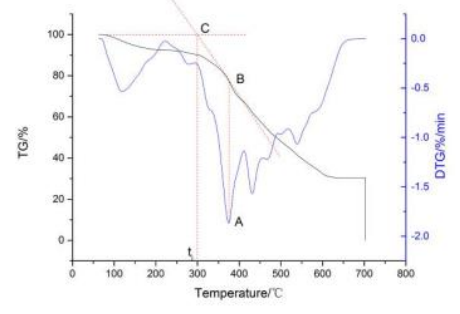

Figure 7 Condition

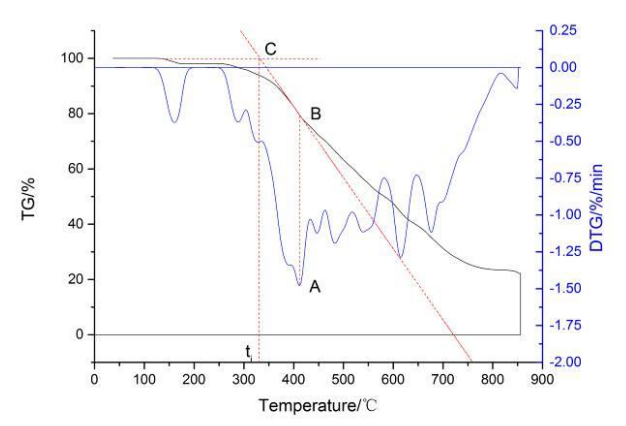

Figure 8 Condition

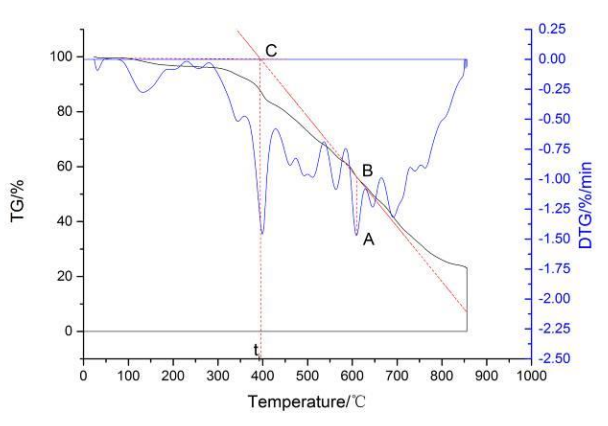

Figure 9 Condition

The firing tempretures of Ulagar: Shaltara (1: 1), Ulagar: Schaltala (1: 2), Ulagar: Schaltala (1: 4), Ulagai: Gepu coal $(2: 1)$ and Ulagai: Gepu coal $(1: 1)$ are: $320{ }^{\circ} \mathrm{C}, 298{ }^{\circ} \mathrm{C}, 300{ }^{\circ} \mathrm{C}, 335{ }^{\circ} \mathrm{C}$ and $400{ }^{\circ} \mathrm{C}$

\section{Ignition Temperature of Three Kinds of Mixed Coal}

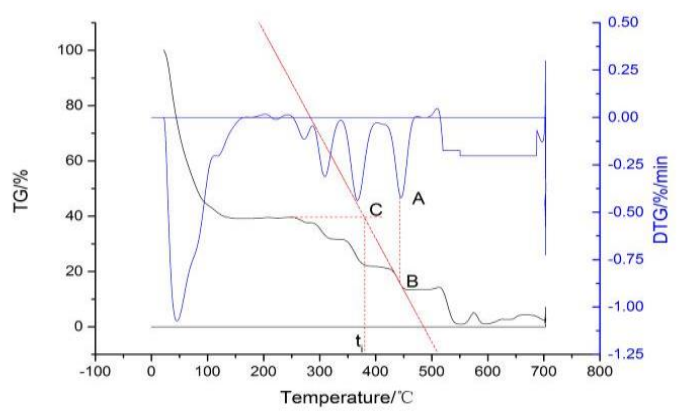

Figure10 Condition

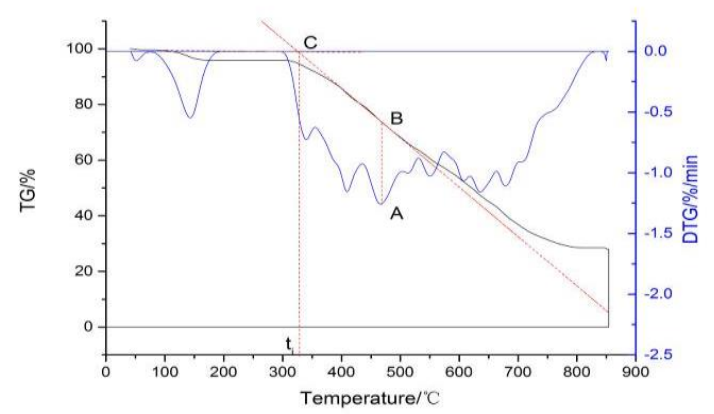

Figure 11 Condition

The firing temperatures of Ulagar: Shaltara: Ge Punching (1: 1:1) and Ulagai: Shaltala: Ge paving (1: 2: 1) are: $375{ }^{\circ} \mathrm{C}$ and $330{ }^{\circ} \mathrm{C}$

In summary, when the Shanxi Ge Pu bituminous coal was mixed into the Hesi Wulai lignite alone, they should be mixed with the Shaltara in order to meet all the requirements of the burning characteristics, so that combustion was more stable. This shows that the greater the proportion of coal in the coal, the better the combustion performance, so it need to design a reasonable proportion for the power plant blending industry to provide theoretical basis.

\subsection{Industry Analysis}

Industrial analysis is an important parameter for coal classification, quality and pricing. According to industry analysis indicators, we can basically grasp the nature and characteristics of various coal. The industrial analysis of this test coal is shown in Table 2. 
Table 2 Industrial Analysis Data for Mixed Coal

\begin{tabular}{|c|c|c|c|c|c|c|}
\hline Project & Symbol & Unit & Design coal & Hezig Ura coal & Shaltara coal & Shanxi Ge Pu coal \\
\hline Moistur-e & Mad & $\%$ & 14.20 & 17.58 & 13.57 & 12.82 \\
\hline Volatile-s & Vdaf & $\%$ & 38 & 41.80 & 31.57 & 22.50 \\
\hline Ash & Aar & $\%$ & 15 & 26.74 & 20.57 & 8.20 \\
\hline Fixed carbon & FCd & $\%$ & - & 9.58 & 9.81 & 15.13 \\
\hline Calorifi-c value & Qnet,ar & MJ/kg & 13.50 & 12.631 & 11.543 & 14.236 \\
\hline Sulfur content & St,ar & $\%$ & 0.43 & 0.56 & 0.48 & 0.42 \\
\hline
\end{tabular}

\subsection{Match Plan}

When the mixed coal ratio was calculated, the economy and environmental protection as the objective function have been taken. However, in most cases, the power plant only considers coal blending costs and uses it as a single objective. For this situation that is not very reasonable, the single-objective coal blending model and the multi-objective mathematical model are discussed below [8].

\begin{tabular}{|c|c|}
\hline Single target coal blending model & Multi - target coal blending model \\
\hline$\left\{\begin{array}{l}\min f_{1}(x)=476 x_{1}+266 x_{2}+806 x_{3} \\
41.8 x_{1}+31.57 x_{2}+22.5 x_{3} \leq 45 \\
26.74 x_{1}+20.57 x_{2}+8.2 x_{3} \leq 25 \\
17.58 x_{1}+13.51 x_{2}+12.82 x_{3} \leq 15 \\
12631 x_{1}+11543 x_{2}+14236 x_{3} \leq 13500 \\
x_{1}+x_{2}+x_{3}=1 \\
x_{i} \geq 0(i=1,2, \ldots, 5)\end{array}\right.$ & $\left\{\begin{array}{l}\min F(x)=\left(f_{1}(x), f_{2}(x)\right)^{T} \\
f_{1}(x)=476 x_{1}+266 x_{2}+806 x_{3} \\
f_{2}(x)=0.56 x_{1}+0.48 x_{2}+0.42 x_{3} \\
41.8 x_{1}+31.57 x_{2}+22.5 x_{3} \leq 50 \\
26.74 x_{1}+20.57 x_{2}+8.20 x_{3} \leq 25 \\
17.58 x_{1}+13.57 x_{2}+12.82 x_{3} \leq 15 \\
12631 x_{1}+11543 x_{2}+14236 x_{3} \leq 13500 \\
x_{1}+x_{2}+x_{3}=1 \\
x_{i} \geq 0(i=1,2, \ldots, 5)\end{array}\right.$ \\
\hline
\end{tabular}

Firstly, the optimal solution of the single objective function is obtained. For a single objective function $f_{1}(x)$, matlab software was used to solve $x=(0.39,0.36,0.25)$, the optimal solution, and the minimum purchase cost of 482.90 yuan / ton; for single objective function $f_{2}(x)$, the matlab software was used to solve the $x_{2}=(0.31,0.42,0.27)$, and the minimum sulfur content of $0.48 \%$. Secondly, the weighting factor $\alpha$ was determined and calculated: $x=(0.358,0.384,0.276)$, the most reasonable cost of coal purchase: 495 yuan / ton, this time, the sulfur content of coal mixed $0.51 \%$. The objective function is the coal purchase price and the sulfur content, the optimal solution is obtained by approximating the Hesheger Ula lignite: Salta pull lignite: Shanxi Gepu bituminous coal (4: 4: 3).

\subsection{Blending Mode}

(1) Mixing ratio before the furnace, the furnace mixed burning

(2) Sub-grinding powder, furnace mixed with burning

(3) Sub-warehouse storage, sub-grinding powder, furnace mixed with burning

(4)Sub-grinding powder, the warehouse blending, furnace mixed with burning

The "sub-grinding powder, sub-warehouse storage, furnace mixed" way was selected by the test, all kinds of coal into the furnace alone, and it was a different coal classification volume to the coal bunker. Do not consider the different coal blending into the same coal bunker, which is mainly due to the characteristics of mixed coal after the complex, and the current theoretical study is not matured.

\section{Conclusion}

(1)Through the thermogravimetric analysis of mixed coal can be obtained in Shanxi Gepu bituminous coal mixed into the Hezig Ura lignite coal, should be mixed with the Shaltara. 
(2)Through the multi-objective decision-making method, the proposed ratio is Hezig Ura lignite coal: Shaltara lignite coal: Shanxi Gepu bituminous coal $=(4: 4: 3)$, which provides a more efficient and safe mixed coal blending scheme for the future operation of mixed coal in power plant, it is suitable for long-term use.

\section{Acknowledgements}

The programme [Improving the Combustion Mode and Security Running Control Strategy to Decrease the Pollution in Northeast of China (UK-CIAPPL201)] was supported by the Royal Academy of Engineering under the UK-China Industry Academia Partnership Programme scheme.

This work was supported by Chinese Scholarship Council (No.201706175069).

\section{References}

[1]. A.Bogot,R.P.Hensel.Combustion in Blending Coals to Meet $\mathrm{SO}_{2}$.mission Requirement Combustion. 1978(7):934-939.

[2]. D.G.Xiang.Current Status of Coal Combustion Technology in the United States-- Report to the United States.1988 (4):3-12.

[3]. P.A.He,Y.P.Dong.A Study of Coal Combustion Technology in Japan.1988(4):37-66.

[4]. Y.G.Xu. "Study on Combustion Characteristics and Proportion of Blended Coal,"Ph.D.thesis,Kun Ming: Kunming University of Science and Technology,2007.

[5]. K. Zhu."Experimental study of burnout characteristics and optimization of coal mix ratio," Ph.D. thesis, Wu Han: Huazhong University of Science and Technology, 2007.

[6]. L.T.Li."Experimental Study on Slagging Process of Blended Coal,” Ph.D. thesis, Hang Zhou: Zhejiang University, 2015.

[7]. K.f.Cen,J.R.Fan.Principle and calculation of fouling, slagging, abrasion and corrosion of boilers and heat exchangers.Bei Jing: Science Press, 1994.

[8]. Y.D.Hu.Multi objective optimization method Joumal of Shanghai Jiaotong Unversity, 1981: 140-150. 